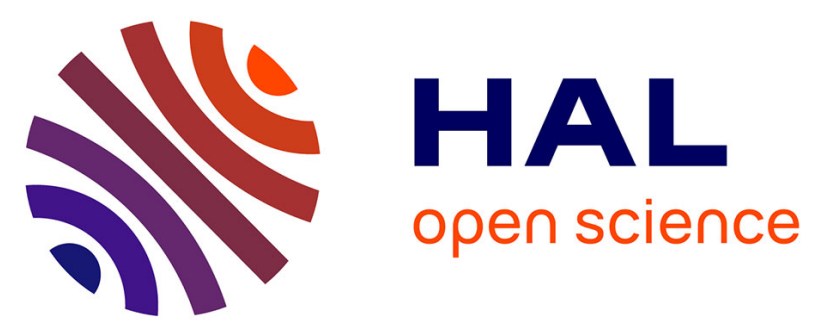

\title{
THE POLARISABILITY OF IRIDIUM NEUTRAL ATOMS AND THEIR VAN DER WAALS INTERACTION WITH A TUNGSTEN SURFACE MEASURED BY F.I.M
}

J. Bardon, M. Audiffren

\section{- To cite this version:}

J. Bardon, M. Audiffren. THE POLARISABILITY OF IRIDIUM NEUTRAL ATOMS AND THEIR VAN DER WAALS INTERACTION WITH A TUNGSTEN SURFACE MEASURED BY F.I.M. Journal de Physique Colloques, 1984, 45 (C9), pp.C9-245-C6-249. 10.1051/jphyscol:1984941 . jpa00224421

\section{HAL Id: jpa-00224421 https://hal.science/jpa-00224421}

Submitted on 1 Jan 1984

HAL is a multi-disciplinary open access archive for the deposit and dissemination of scientific research documents, whether they are published or not. The documents may come from teaching and research institutions in France or abroad, or from public or private research centers.
L'archive ouverte pluridisciplinaire HAL, est destinée au dépôt et à la diffusion de documents scientifiques de niveau recherche, publiés ou non, émanant des établissements d'enseignement et de recherche français ou étrangers, des laboratoires publics ou privés. 


\title{
THE POLARISABILITY OF IRIDIUM NEUTRAL ATOMS AND THEIR VAN DER WAALS INTERACTION WITH A TUNGSTEN SURFACE MEASURED BY F,I,M.
}

\author{
J. Bardon ${ }^{\star}$ and M. Audiffren \\ CRMC2-CNRS, Campus de Luminy, case 913, 13288 Marseizle cedex 09, France \\ *also Université de Provence, U.E.R. de Physique, 13003 Marseizle, France
}

RESUME : Nous dêcrivons la mesure, en microscopie ionique de champ, de la polarisabilité a d'adatomes neutres d'iridium et de leur constante d'interaction de van der Waals $C$ avec une surface de Tungstène. Les valeurs trouvêes sont : $\alpha=8 \pm 1 \AA^{3}$ et $\mathrm{C}=10 \pm 3 \mathrm{eV} \AA^{3}$.

ABSTRACT : We describe the measurement, by Field Ion Microscopy, of the polarisability $\alpha$ of neutral Iridium atoms and of their Van der Waals interaction constant $C$ with a Tungsten surface. The values obtained are $\alpha=8 \pm 1 \AA 3$ and $\mathrm{C}=10 \pm 3 \mathrm{eV} \AA^{3}$.

\section{INTRODUCTION}

The static polarisability of neutral atoms is an important quantity involved in many phenomena related to atomic beams. It has been theoretically calculated for many atoms $/ 1,2 /$, but reliable experimental data are scarce and mainly limited to the noble gases /3/ and alkali metals /4/. The reason is the difficulty of obtaining the strong gradient of electric field and the good spatial resolution of neutral atoms detectors that are needed. Some attempts have been made first by Drechsler /5/ a long time ago by using a FEM tip to produce the electric field gradient and a glass plate as a detector but the accuracy was poor ; Bermond $/ 6 /$ measured the polarisability of $\mathrm{Pb}$ using a F.E.M. tip also as a detector.

We thought that the Field Ion Microscopy was ideally suited for such measurements because field gradients and spatial resolution are inherent to this instrument. The F.I.M. tip was used to obtain the field gradient and to determine the location of Ir atoms reaching the tip. Thus, we have measured the polarisability of neutral Ir atoms and also the Van der Wals constant of attraction between these atoms and the tungsten surface of the tip.

\section{EXPERIMENTAI}

The principle of the measurement and the experimental device are schematized in Fig. 1. A source of Iridium atoms is set on the side of a tungsten field ion microscope tip, far enough for the velocities of the incoming atoms to be considered as parallel. In the absence of an electric field during the deposition, one could expect that all the Ir atoms would impinge on the <Sunny> part (S-part) of the tip limited by the $\mathrm{xOz}$ plane. When an electric field is applied to the tip, the electric field gradient curves the atomic trajectories and some atoms must arrive into the geometrically shadowed region (D-part).

Experimental details have been described elsewhere /7/. The source temperature was $2200 \pm 30 \mathrm{~K}$ and was monitored during the depositions by a Twocolour pyrometer, giving an excellent reproducibility for the number of deposited atoms. 


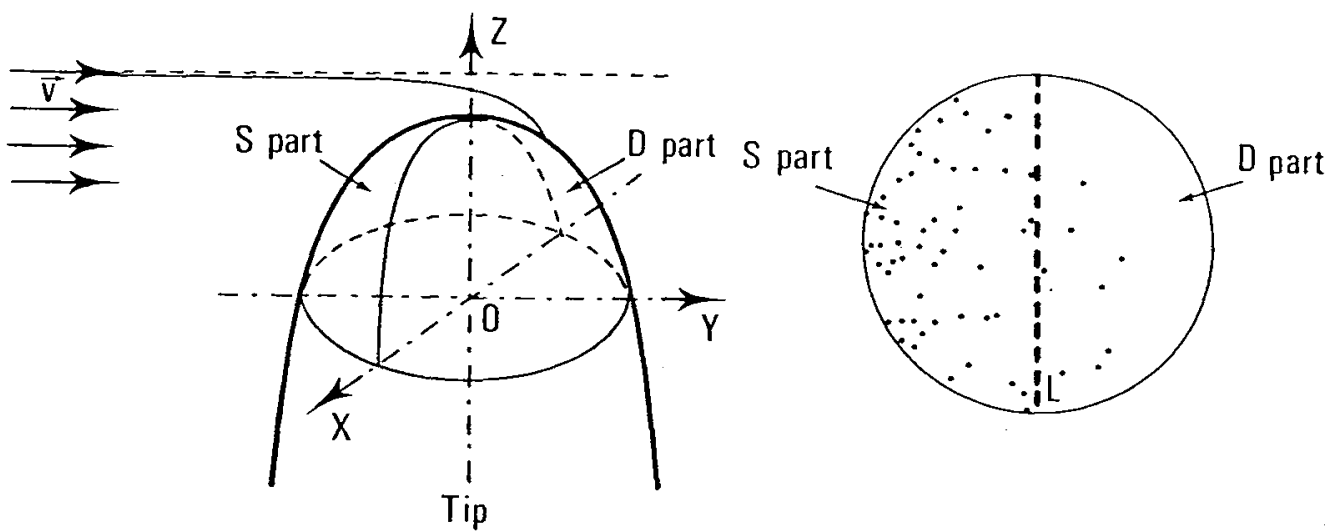

Figure 1 a a

Figure

Fig. 1 a) Principle of the measurement; without interaction the atoms incoming with velocities paralle1 to the Oy axis should strike the tip in the S-part on 1 . Fig. 1 b) Example of a pattern obtained after one deposition; each dot corresponds to one adatom. The sum of $d$ is the parameter which was used to determine the polarisability.

The localization of the L line /7/ was made by using the totality of the projections with and without the electric field applied. The total number of adatoms in the D-part was 516 and 2820 in the S-part.

The depositions were made up to $0.3 \mathrm{~V} / \mathrm{A}$ with positive and negative fields. The results were the same, giving evidence that the interaction is effectively a function of the square of the field. These measurements also show that, as expected from the Saha-Langmuir relation, the number of ions emitted by the source is negligible. We were prevented from using higher negative values of the field because of the ionization of the incoming neutral atoms by the FEM current.

With a positive tip, the field was varied up to $0.65 \mathrm{~V} / \mathrm{A}$. It was calibrated against the BIV and the beginning of the field evaporation. We assumed a value of $4.5 \mathrm{~V} / \AA$ for the BIV. By increasing the field, the total number $\mathrm{N}_{t}$ and $\mathrm{N}_{\mathrm{d}}$ the number in the D-zone of observed Ir adatoms increase up to $0.58 \mathrm{~V} / \AA$. They decrease sharply above this value. This decrease is due to the ionization of the atoms incoming in the vicinity of the tip. This interpretation is confirmed by the fact that the ratio $\mathrm{N}_{\mathrm{d}} / \mathrm{N}_{\mathrm{t}}$ of the number of adatoms in the $\mathrm{D}$-zone to the total number also decreases, the atoms incoming in the D-zone being exposed to the high electric field for a longer time than the other ones.

Between two depositions, the adatoms were field desorbed. However the field needed to desorb Ir adatoms is of the same magnitude than the evaporation field of tungsten. To prevent a rapid growth of the tip, we used the method described by Tsong and Walko /8/ : heating the tip at $300 \mathrm{~K}$ with the imaging field applied drives the adatoms to the ledges of the faces where they are immediately field desorbed.

For each value of the electric field, ten depositions were made. The mean number of atoms deposited in the D-part was 90 and the mean total number of adatoms in a $32^{\circ}$ - wide zone around the apex of the tip was 450 .

Iridium is well suited to these measurements due to the high values of the fields needed to ionise the neutral atoms and to desorb the adatoms. The same experiments with tantalum and tungsten are limited to a narrower range of electric field ( $0.3 \mathrm{~V} / \AA$ ) and micrographs taken at field further down from of the BIV are more 
difficult to observe with the twocolour superposition method $/ 9 /$.

RESULTS

As already described for tantalum atoms /7/, Iridium adatoms exist in the Dzone after the depositions without electric field. The ratio of the number of these adatoms to the total number in a $32^{\circ}$ zone around the apex of the tip is 0.11 .

This phenomenon was modelised with a Van der waals attraction, assuming an interaction energy of the form $\mathrm{W}=-\mathrm{C} / \mathrm{z}^{3} . \mathrm{C}$ is the constant of interaction and $z$ the distance of the atom to the surface of the tip. The Maxwellian distribution of the velocities of the atoms leaving the source was taken into account. The calculation is threedimensional according to the results of Bermond /11/ who demonstrated the importance of non planar trajectories.

The value of the constant that we have obtained is $c=10 \pm 3 \mathrm{eV} \AA^{3}$.

We used the same type of calculation to determine the value of the polarisability. The total energy was taken as the sum of the Van der Waals energy and the polarisation energy $1 / 2 \alpha F^{2}$. The tip was represented by an hyperboloild superimposed to a cone $/ 12 /$; this representation enabled us to obtain the spatial repartition of the electric field analytically. The value of the form factor was 0.1 . Some tests have demonstrated that this value can vary from 0.06 to 0.18 without noticeable effects on the results. With this model, we calculated a quantity proportionnal to the sum of the distances of the adatoms to the L-1ine for different values of $\alpha$ and F. A correction was made to transform the true calculated distances to a stereographic projection according to Muller and Tsong /9/.

A first attempt to experimentally measure the ratio $\mathrm{N}_{\mathrm{d}} / \mathrm{N}_{\mathrm{t}}$ versus the field failed to give sufficiently precise results. The statistical scatter of the experimental points was such that a prohibitive number of depositions would have been necessary.

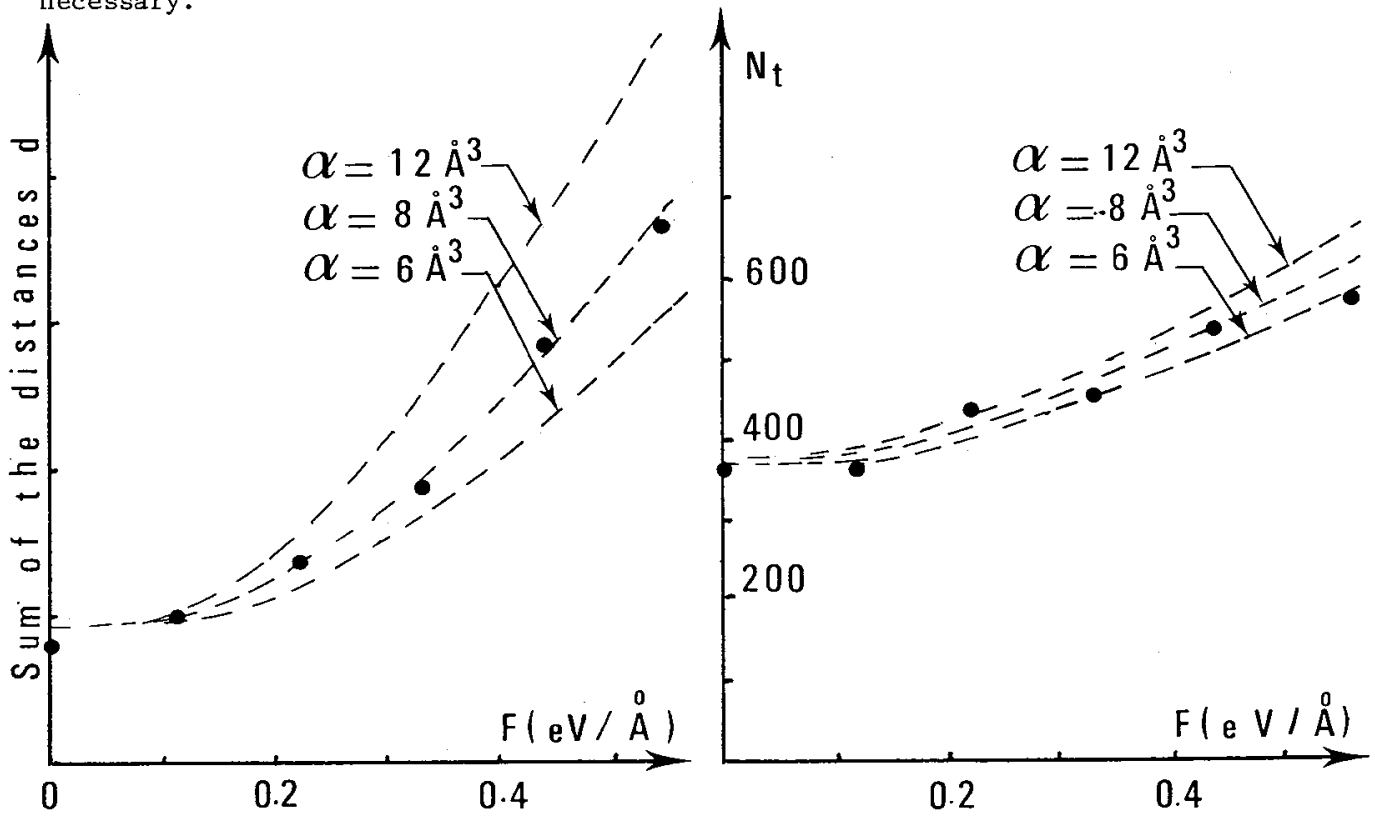

Fig. 2 : Sum of the distances of the adatoms in the D-zone to the I line versus the electric field : experiFig. 3 : Total number of adatoms versus electric field. experimental points, mental points, ---- theoretical curves --- theoretical curves 
Thus, we measured the distances $d$ to the L-1ine of all the adatoms in the Dzone and calculated the sum of these distances for al1 the micrographs taken after depositions at same field. Results are given in Fig. 2 together with the calculated sums of distances. Fig. 3 shows the total number of adatoms versus the field.

As expected, the dispersion of the experimental results is more important in Fig. 3 than in Fig. 2. But the important point is that the two curves agree with each other. It is Iikely that an error in the model or an important effect of the differences in the local radius of curvature would give important discrepancies between the two figures.

The best fit for the value of $\alpha$ in Fig. 2 is obtained for $\alpha=8 \mathrm{~A}^{3}$.

\section{DISCUSSION}

The presence of adatoms in the D-part of the tip has already been observed $113,14 /$. The validity of the interpretation by the Van der Waals interaction has been carefully discussed /7/ in a previous paper on tantalum. Since, we also have rough1y calculated the effects of patchfields /15/, step dipole interactions /16/ and recoil effects $/ 17 /$. These effects could hardly involve an interaction energy greater than $3 \%$ of the polarisation and Van der Waals energies.

A graphical simulation of the trajectories showed that the Van der Waals interaction is short ranged $(\sim 30 \AA)$. Consequently we did not checked a $\mathrm{C} / \mathrm{z}^{4}$ relation ; the retardation effects being only expected to have noticeable effects for $z$ greater than $800 \mathrm{~A}$. As for tantalum and for the same reasons, it is beyond the scope of this paper to calculate a theoretical value of $C$ for comparison with our experimental result. However the order of magnitude of $C$ is reasonable and the value obtained is smaller than for tantalum. We could expect this result because the value of the static polarisability is probably also smaller for Ir than for $\mathrm{Ta}$ as theoretically calculated /1/ and experimentally confirmed by our preliminary results on Ta.

It is difficult to compare the value of $C$ with those obtained by different methods ; indeed, $C$ was only measured for noble gas interaction with alkali halides surfaces $/ 18,19 /$ and alkali metals with metallic surfaces $/ 20,21 /$.

The value obtained for the polarisability is in good agreement with the theoretical result $7 \AA^{3}$ given by Miller and Bederson /1/. The curves of Fig. 2 permit to estimate an error of about $12 \%$. Thus $\alpha=8 \pm 1 \mathrm{eV} \AA^{3}$.

We stress the fact that the determination of the Van der Waals constant $C$ and the value of the polarisabilily a do not involve adjustable parameters. The knowledge of $\mathrm{C}$ is mandatory to obtain the value of $\alpha$, but the determination of $\mathrm{C}$ is done independantly by the measurements without electric field.

\section{CONCLUSION}

We have, for the first time to our knowledge, measured the Van der Waals constant of interaction between Irjdium atoms and a metallic surface. We also have measured for the first time, with a good accuracy, the value of the polarisability of Ir atoms. The agreement between experimental and theoretical results is good. The use of the sum of distances to the $L$ line reduces the number of experimental runs required to obtain an accurate value of the polarisability. In its present form, the method is limited to those adatoms that are readily imaged by FIM. It could be extended to other atoms by using a Field Desorption Microscope.

\section{ACKNOWLEDGMENTS}

The authors very much appreciated helpful discussions with Dr. R. Morin and Dr. J. Bermond. Throughout the investigation, they also thank Pr. M. Drechsler for his constant interest in the development of this work. 


\section{BIBLIOGRAPHY}

/1/ MILLER, T.M., BEDERSON, B., Adv. in Atomic and Mo1. Phys. vo1. 13, Bates D.R. and Bederson B., ed., Academic Press N.Y. 1977

/2/ TEACHOUT, R.R., and PACK, R.T., Atomic Data 3 (1975) 195

/3/ MOLOF, R.W., SCHWARTZ, H.L., MILLER, T.M. and BEDERSON, B., Phys. Rev. A 10 (1974) 1131

/4/ HALL, W.D., ZORN, J.C., Bu11. Am. Phys. Soc. 13 (1968) 21

/5/ DRECHSLER, M., MULLER, E.W., Z. Phys. 132 (1952) 195

/6/ BROSSE, J.B., BERMOND, J.M., DRECHSLER, M. , Rev. de Physique App1. 11 (1976) 677

/7/ BARDON, J., AUDIFFREN, M., J. de Physique -Lettres 44 (1983) L883

/8/ TSONG, T.T., WAIKO, R.J., Phys. Stat. Sol. 12 (1972) 111

/9/ MULLER, E.W., TSONG, T.T., Field Ion Microscopy, Am. Elsevier Pub. Company, N.Y., 1969

/11/ BERMOND, J.M., Rev. de Physique App1. 17 (1982) 491

/12/ DRECHSLER, M., HENKEL, E., Z. Angew. Phys. 6 (1954) 341

/13/ GURNEX, T., HUTCHINSON, F., YOUNG, R.D., J. Chem. Phys. 42, 11 (1965) 3939

/14/ EHRIICH, G., in Metal Surfaces (ASM Metals Park, Ohio) $1 \overline{963}$

/15/ MEHL, M.J., SCHAICH, W.L., Phys. Rev. Al6 (1977) 921,

POLITZER, J., FEUCHTSWANG, T.E., Surf. Sci. 19 (1970) 443

/16/ KRAHL-URBAN, B., WAGNER, H., BUTZ, R., Surf. Sci. 93 (1980) 423

/17/ MANSON, J.R., RITCHIE, R.H., Phys. Rev. B 29, 2 (1984) 1084

/18/ HOINKES, H., Rev. Mod. Phys. 52 (1980) 933

$/ 19 /$ HoINKES, H., WILSCH, H., Proc. 4th Int. Conf. on Solid Surf., Cannes (1980), Degras D.A., Costa, M., Eds. S.F.V. Paris

/20/ RASKIN, D., KUSH, P., Phys. Rev. 179 (1969) 712

/21/ SHIH, A., RASKIN, D., KUSH, P., Phys. Rev. A $\underline{9}$ (1974) 652 